\title{
Rat CNS White Matter, But Not Gray Matter, Is Nonpermissive for Neuronal Cell Adhesion and Fiber Outgrowth
}

\author{
Tiziana Savio and Martin E. Schwab \\ Brain Research Institute of the University of Zurich, CH-8029 Zurich, Switzerland
}

In adult mammalian CNS, axons mostly fail to regenerate after injury, while in the PNS they often succeed in reaching their previous targets. Crucial differences are present in the local tissue microenvironment of CNS and PNS. To investigate the substrate properties of nervous tissue for neuronal adhesion and fiber growth, we used frozen sections of rat CNS and PNS as culture substrates for neuroblastoma cells and for sympathetic and dorsal root ganglia. The results showed that CNS white matter from adult rat spinal cord, cerebellum, forebrain, or optic nerve did not allow cell adhesion and axonal elongation. In contrast, gray matter areas, sciatic nerve, and also trout CNS white and gray matter were permissive substrates.

To delineate the tissue components of white matter involved in this nonpermissive substrate effect, newborn rats were injected for $13 \mathrm{~d}$ with the antimitotic agent 5-azacytidine. This treatment strongly reduced the oligodendrocyte population and the myelin content of the spinal cord. The immunoreactivity for specific oligodendrocyte and astrocyte markers confirmed the selective suppression of oligodendroglia in these rats. Neuroblastoma cells plated on spinal cord sections taken from these animals were no longer exclusively localized on the gray matter but were also found on regions normally rich in myelin.

A significant reduction of the white matter nonpermissive substrate effect was also obtained by the monoclonal antibody IN-1 directed against 2 defined myelin proteins with inhibitory substrate properties (Caroni and Schwab, 1988b). Our results, therefore, show that, in the adult mammalian CNS, cell adhesion and axonal elongation are prevented by white matter components, which are, at least in part, associated with oligodendrocytes and myelin.

Adult CNS of higher vertebrates has long been known to lack significant axonal regrowth after lesion. This contrasts with the presence of regeneration in the peripheral nervous system and in lower vertebrates such as fish and amphibians. The restriction of axonal elongation in the adult CNS is not due to an intrinsic

\footnotetext{
Received Mar. 7, 1988; revised Sept. 9, 1988; accepted Sept. 13, 1988.

We thank Dr. F. Omlin (Lausanne) and Dr. M. Schachner (Heidelberg) for the gift of antibodies. We are grateful to Mrs. S. Kaufmann for typing the manuscript, to Mr. H. Künzli for photographic assistance, to Dr. P. Caroni, Mrs. A. LoMonico, $P$. Paganetti, and Dr. P. Sonderegger for critically reading the manuscript. This work was supported by the Swiss National Foundation for Scientific Research (Grant No. 3.043-0.84) and Grants from the Swiss Multiple Sclerosis Society and the Dr. E. Slack Gyr Foundation.

Correspondence should be addressed to Dr. Tiziana Savio, Brain Research Institute of the University of Zurich, August-Forel-Strasse 1, 8029 Zurich, Switzcrland.

Copyright (C) 1989 Society for Neuroscience $0270-6474 / 89 / 041126-08 \$ 02.00 / 0$
}

incapability of axons to elongate (Ramón y Cajal, 1928; Benfey and Aguayo, 1982; Richardson et al., 1984; So and Aguayo, 1985). However, the responsible factors are still controversial. Both soluble molecules and substrate components (Liesi, 1985a; Carbonetto et al., 1987; Sandrock and Matthew, 1987) are currently proposed.

Although soluble molecules, such as NGF, are necessary for survival and process formation of certain neuronal types (LeviMontalcini and Angeletti, 1968; Thoenen and Barde, 1980; Johnson et al., 1986), their presence in vitro is not sufficient to allow neurite growth into explants of CNS (Schwab and Thoenen, 1985). Therefore, substrate components may play an important role, and they could be of 2 types with opposite effects on axonal elongation: favorable substrates present only in PNS and during CNS development, and/or nonpermissive components present in differentiated CNS. While many substances and cellular types have been proposed as fundamental for axonal growth (Daniloff et al., 1986; Smith et al., 1986), less attention has been paid to nonpermissive mechanisms, except for a postulated barrier formation by scarring astrocytes (Reier et al., 1983; Liuzzi and Lasek, 1987). Recently, tissue culture experiments pointed to a new direction: CNS myelin and differentiated oligodendrocytes were shown to represent an inhibitory substrate for neurite outgrowth and nerve cell adhesion (Schwab and Caroni, 1988). This effect was mediated by membrane proteins present on the surface of these myelin-forming cells (Caroni and Schwab, 1988a, b).

In order to investigate the substrate properties of various regions of the CNS for adhesion of neurons and elongation of neurites, frozen sections were used as culture substrates for neuroblastoma cells and sympathetic and sensory neurons. It has already been shown (Carbonetto et al., 1987) that it is possible to grow neurons on frozen sections and that adult rat PNS tissue (sciatic nerve) and fish CNS are much better substrates than adult rat optic nerve.

In this study we show that adult rat CNS white matter, but not gray matter, from various parts of brain and spinal cord is a nonpermissive substrate for adhesion of neurons and neuroblastoma cells and for axon elongation. This property is linked to the presence of oligodendroglia and CNS myelin and is significantly reduced by an antibody against CNS myelin inhibitory substrate components (IN-1 antigens; Caroni and Scbwab, 1988b).

\section{Materials and Methods}

Frozen sections

Adult, newborn, 14-d-old, and 1-month-old Lewis rats and mature trout wcrc uscd as tissuc sources. Injection of 5-azacytidinc (Sigma, St. Louis), to prevent oligodendrocyte development (Black et al., 1986), was done 


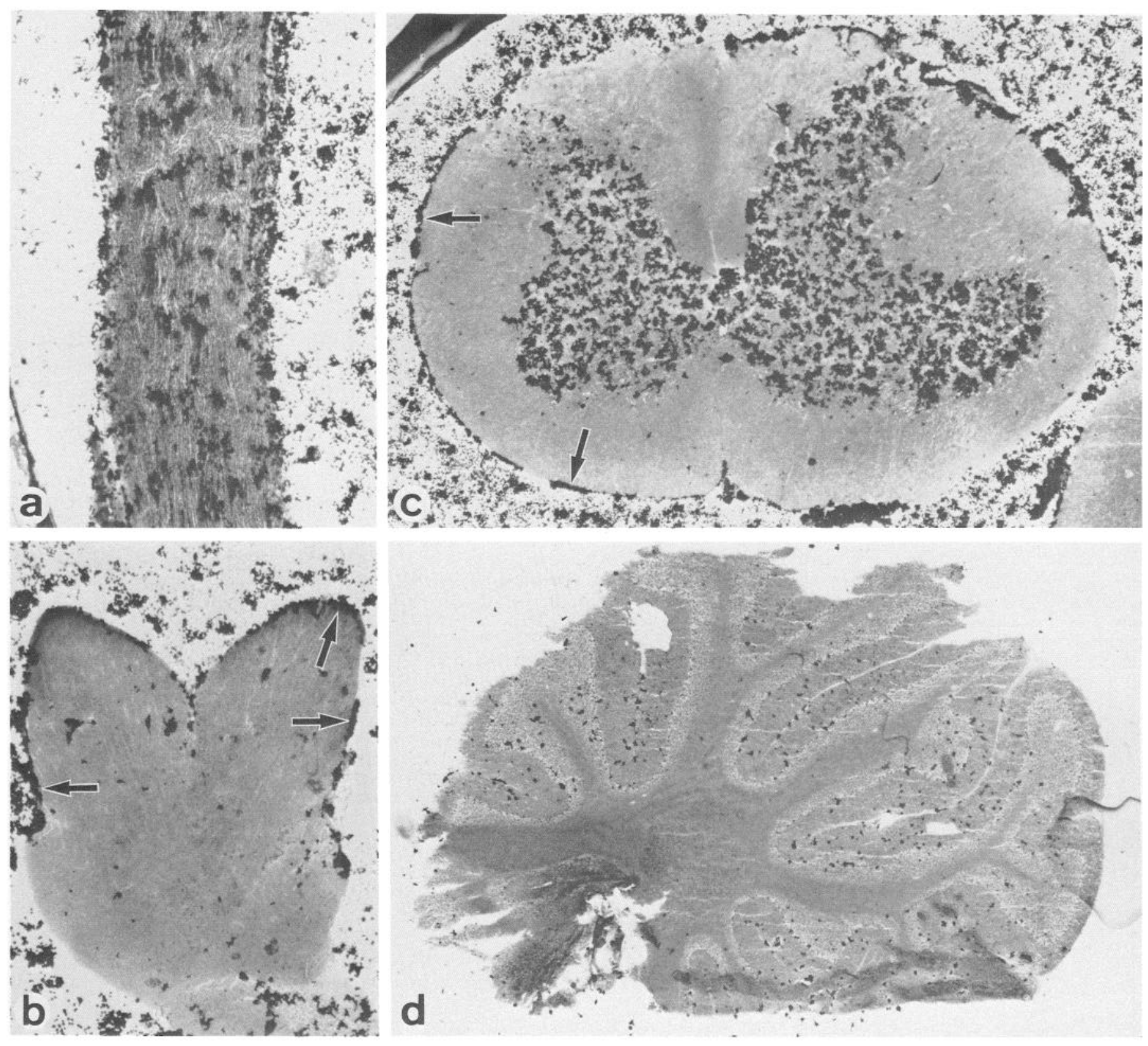

Figure 1. Neuroblastoma cells cultured for $2 \mathrm{~d}$ on frozen sections of adult rat sciatic nerve (a), optic nerve (with optic chiasm) (b), spinal cord $(c)$, and cerebellum $(d)$. A great number of cells adhere to sciatic nerve tissue, while only few are sitting on optic nerve sections $(a, b)$. Many cells adhere at the optic nerve surface to remnants of the meninges (arrows). Neuroblastoma cells cultured at high cell density on spinal cord show a strong preference for gray matter (c), as they do for cerebellar gray matter $(d)$. Arrows in $c$ as in $b$. Staining, Cresyl violet. Magnification, $a$ and $b$, $\times 36 ; c, \times 23 ; d, \times 17$.

daily ( $5 \mu \mathrm{g} / \mathrm{g}$ body weight in Hank's solution, injected intraperitoneally) from day 1 to day 13 . Rats were killed by an overdose of ether; brain, spinal cord, and optic and sciatic nerves were rapidly removed, mounted with Tissue-Tek, and immediately frozen in liquid nitrogen. Twentymicron sections were cut on a cryostat, mounted onto round glass coverslips (10 mm diameter) and placed into wells of 4-well $35 \mathrm{~mm}$ culture dishes (Greiner, Nürtingen, FRG). Substrates were stored, if necessary, at $-20^{\circ} \mathrm{C}$ and washed extensively with culture medium prior to use.

\section{Preparation of cell cultures}

Mouse NIH $3 T 3$ cells and neuroblastoma cells (line NB-2A) cultured in Dulbecco's modified Eagle's medium (DMEM) with $10 \%$ fetal calf serum (FCS) were detached from the culture flasks by a brief treatment with $0.1 \%$ trypsin in $\mathrm{Ca} / \mathrm{Mg}$-free-Hank's solution, followed by addition of DMEM/FCS. After washing, the cells were added onto the sections (50,000 to 100,000 cells per well) in $100 \mu \mathrm{l}$ DMEM/FCS and incubated for $2 \mathrm{~d}$ at $37^{\circ} \mathrm{C}$.

Preincubations of sections with $100 \mu$ monoclonal antibodies IN-1 (Caroni and Schwab, 1988b) or $\mathrm{O}_{4}$ (Sommer and Schachner, 1981) used as hybridoma culture supernatants were done twice for $3 \mathrm{hr}$ at $37^{\circ} \mathrm{C}$. Then, NB-cells in $50 \mu \mathrm{l}$ medium were added to the sections together with $50 \mu \mathrm{l}$ antibody and incubated for $15 \mathrm{hr}$ at $37^{\circ} \mathrm{C}$.

Two different types of nerve cells were cultured on the sections: sympathetic neurons from superior cervical ganglia (SCG) of newborn rats, and sensory neurons from dorsal root ganglia (DRG) of 12-d-old chicken embryos or of newborn rats. SCG and DRG were dissected and dissociated into single cells as described (Mains and Patterson, 1973; Schwab and Thoenen, 1985) and then added to the sections at 10,000-30,000 cells/well.

In some experiments, DRGs were dissected from the chicken em- 


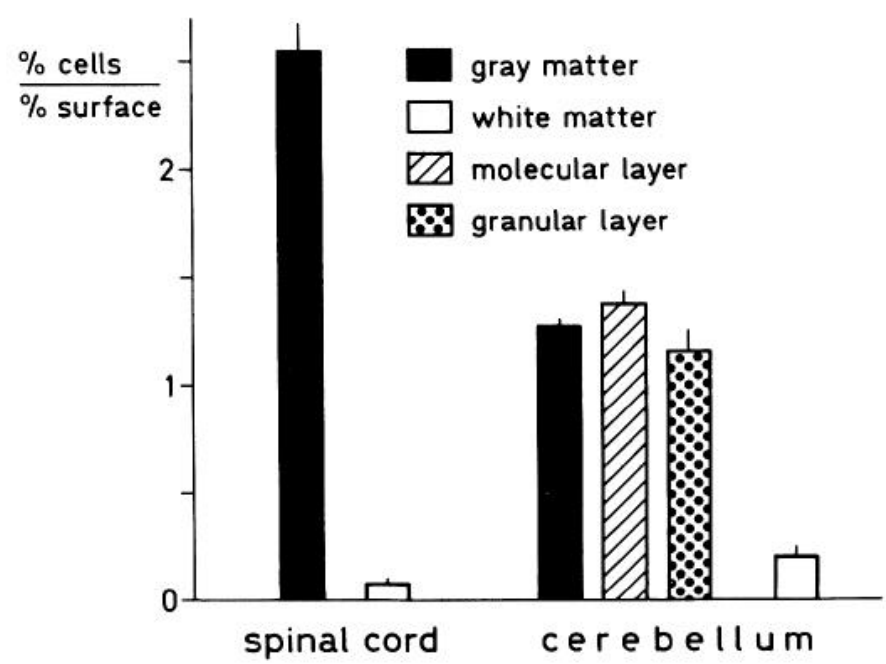

Figure 2. Quantitative determination of neuroblastoma cell density on white and gray matter of adult rat spinal cord and cerebellar sections. Each column represents the relative quantity of cells with respect to the surface of the respective structure (see Materials and Methods). Mean \pm SEM of 3 spinal cord sections and of 7 cerebellar sections. The difference between gray and white matter regions is evident.

bryos, cleaned from adhering tissue, and carefully placed onto the sections. Both dissociated neurons and intact ganglia were incubated on sections for 6-15 d in the following culture medium: enriched $L_{15}$ medium (Mains and Patterson, 1973) with 5\% rat serum, penicillin (100 $\mathrm{U} / \mathrm{ml})$, streptomycin $(100 \mu \mathrm{g} / \mathrm{ml})$, and NGF (2.5 S NGF, 50 or $100 \mathrm{ng} /$ $\mathrm{ml})$. In order to suppress the growth of Schwann cells contaminating the dissociated neuron preparation, cytosine arabinoside (Ara-C, 10-5 M) was included.

\section{Staining and evaluation of results}

Sections with NB-2A or 3T3 cells were fixed in formalin $(4 \%$ in $0.1 \mathrm{M}$ phosphate buffer with $5 \%$ sucrose), rinsed in phosphate buffer, and, after dehydration with alcohol and rehydration, stained with cresyl violet for 10 min. NB-2A adhesion was quantified by counting somata attached to tissue sections and measuring surface areas with a data tablet (Bit Pad Two, Summagraphic Co.). The percentage of cells on different regions (white and gray matter, molecular and granular layer of the cerebellum) was calculated. The data were expressed as the percentage of cells related to the percentage of the corresponding region surface as follows:

$$
N_{x} \cdot S_{\text {tot }} / N_{\text {tot }} \cdot S_{x}
$$

where $N_{x}$ is the cell number on one region (gray matter, white matter, etc.) of one section; $S_{x}$, the surface of the same region; $N_{\text {tor }}$, the total cell number on one section; and $S_{\text {tot }}$, the total surface of one section.

Mean values \pm SEM were then calculated from 3-7 sections chosen randomly. In this way, evaluation of the mean relative presence of cells was influenced neither by the total number of cells on one single section, nor by the different proportions of the various surfaces.

Sections with SCG or DRG neurons or ganglia were fixed with formalin after 6-15 d in culture, rinsed in phosphate buffer and stained with Coomassie blue $(0.5 \%$ in $10 \%$ acetic acid, $30 \%$ isopropanolol) for $5 \mathrm{~min}$.

\section{Immunofluorescence}

Four different marker antibodies and procedures were used: (1) monoclonal antibody $\mathrm{O}_{1}$ against galactocerebroside (GalC) (Sommer and Schachner, 1981; Singh and Pfeiffer, 1985) for oligodendrocytes and myelin; (2) antiserum against the astrocyte marker glial fibrillary acid protein (GFAP) (Ortho Diagnostic System, Raritan, NY); (3) goat antiserum against myelin basic protein (MBP) of rabbit (Omlin et al., 1982); and (4) rabbit antiserum against laminin (Gibco, Paisley, Scotland). In all cases sections from 5-azacytidine-injected rats and controls of the same age were washed twice with $0.1 \mathrm{~m}$ phosphate buffer containing $5 \%$ sucrose and $5 \%$ BSA.

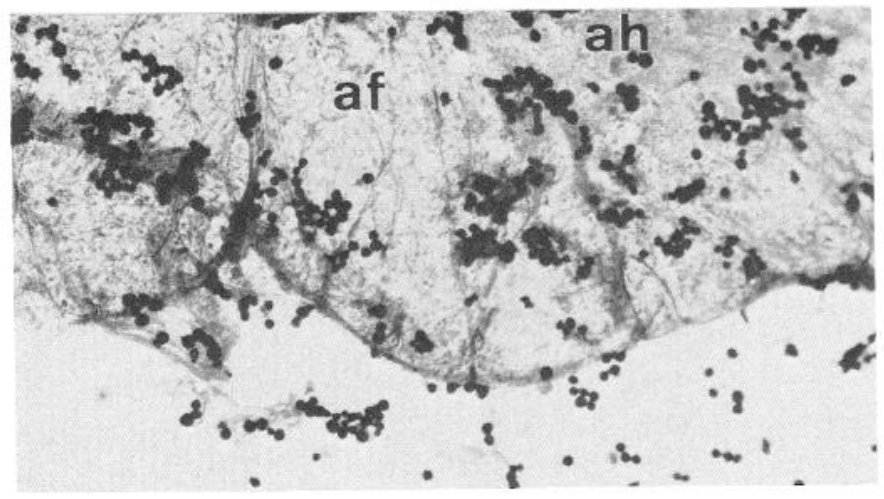

Figure 3. Neuroblastoma cells ( $2 \mathrm{~d}$ in culture) on mature trout spinal cord anterior funiculus $(a f)$ and anterior horn $(a h)$. A random distribution of cells shows the absence of any substrate preference, Staining, Cresyl violet. $\times 75$.

GalC staining. After fixation for $1 \mathrm{hr}$ with $4 \%$ formalin and rinsing with phosphate buffer/sucrose/BSA, sections were incubated for $30 \mathrm{~min}$ at room temperature with undiluted mouse $\mathrm{m}-\mathrm{AB} \mathrm{O}_{1}$ hybridoma supernatant. They were then rinsed twice and incubated with sheep antimouse FITC-linked secondary antibody (Cappel, West Chester, PA; dilution 1:30 in phosphate buffer/sucrose/BSA), washed, and mounted in PBS: glycerol (1:1).

Staining for GFAP. This was performed after fixation in $95 \%$ alcohol with $5 \%$ acetic acid $\left(4^{\circ} \mathrm{C}, 30 \mathrm{~min}\right)$ and rehydration into phosphate buffer by incubating the sections for $1 \mathrm{hr}$ with a rabbit antiserum against GFAP (diluted with phosphate buffer/sucrose/5\% BSA) followed by an antirabbit-FITC-linked secondary antibody (Miles, Naperville, IL).

Staining for $M B P$. After fixation for $10 \mathrm{~min}$ with $4 \%$ formalin and subsequently with $95 \%$ alcohol with $5 \%$ acetic acid $\left(4^{\circ} \mathrm{C}, 30 \mathrm{~min}\right)$ and rehydration into phosphate buffer, sections were incubated for $12 \mathrm{hr}$ with a goat antiserum against MBP (diluted 1:500) and visualized with anti-goat FITC-linked secondary antibody (Cappel).

Staining of laminin. This procedure similar to $\mathrm{O}_{1}$ staining (dilution 1:50); visualizing was accomplished with goat-anti-rabbit-FITC linked secondary antibody (Miles).

\section{Results}

Neuroblastoma cells on sections of adult rat CNS and PNS

NB-2A cells were cultured for $2 \mathrm{~d}$ on adult rat tissue sections taken from spinal cord, cerebellum, cerebral cortex with corpus callosum, and optic and sciatic nerves. Many cells adhered to the sciatic nerve sections, showing a tendency to a linear disposition along the longitudinal axis (Fig. 1a). In contrast, optic nerve sections were almost devoid of cells on the entire surface (Fig. $1 b$ ). Many cells were, however, seen to adhere to the remnants of the meninges at the surface of the optic nerve.

The distribution of NB-2A cells on sections of various CNS regions was very characteristic: while the gray matter was densely covered with cells, white matter regions where almost entirely devoid of cells. This typical picture was found in sections of spinal cord (Fig. 1c), cerebellum (Fig. 1d), and forebrain. During cultivation, many floating, nonadhering cells were present over the white matter regions. Such cells later attached to gray matter or to the glass or were removed by washing at fixation. In most cases, the anatomical disposition of gray matter was "highlighted" by the perfect overlap of the NB-2A cells sitting on it. Lines and groups of cells sitting on the pia bordered the white matter regions without invading them in spinal cord sections (Fig. 1c). The quantitative determination of neuroblastoma cell distribution on spinal cord and cerebellar sections confirms these observations (Fig. 2). 

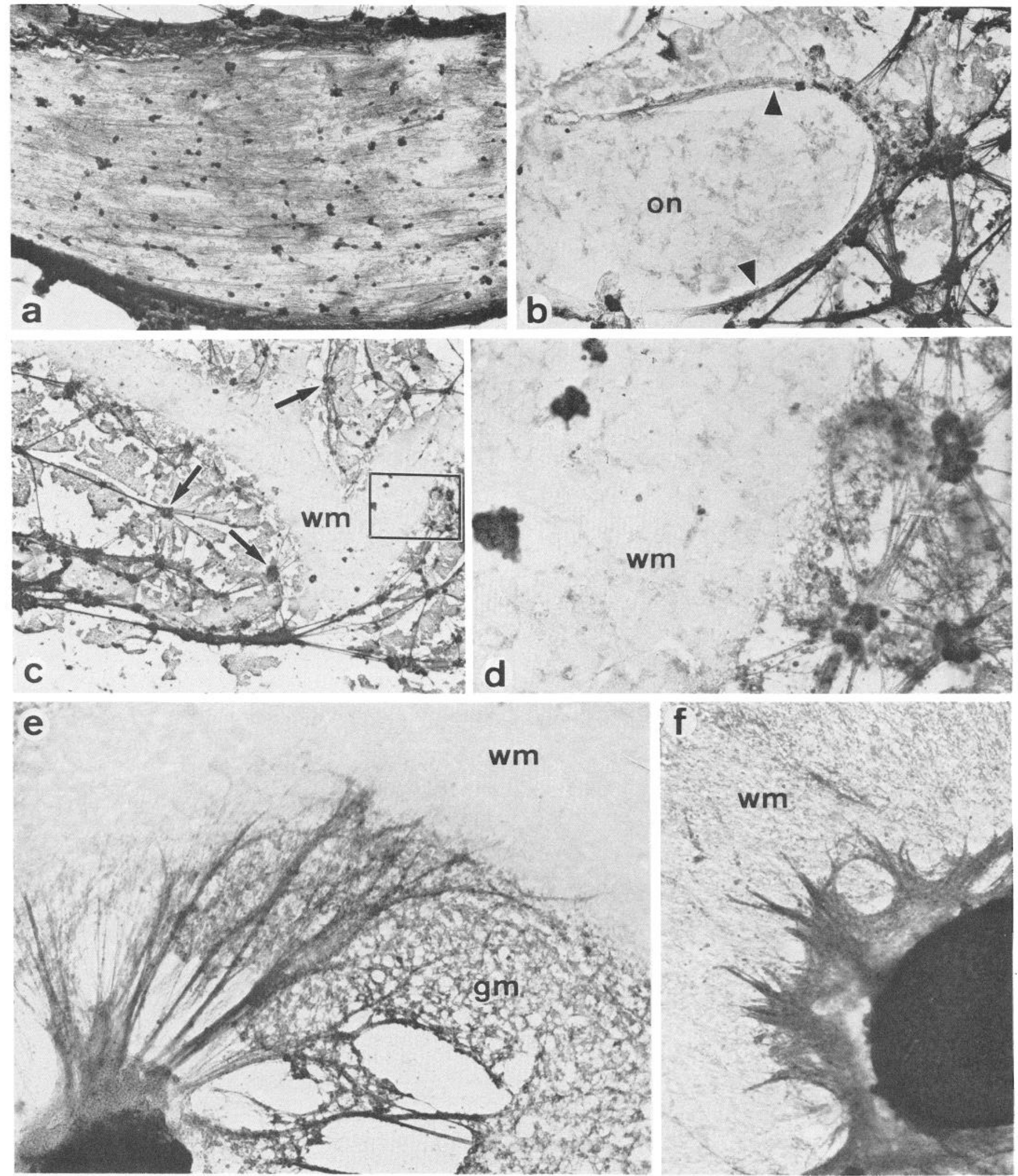

Figure 4. Dissociated newborn rat SCG cells (6 d in culture, in the presence of NGF) adhere and extend processes on adult rat sciatic nerve sections $(a)$ but fail to do so on optic nerve (on) sections $(b)$, while forming an extensive plexus (arrowheads) around the nerve. On CNS tissue, cells and processes are confined to gray matter regions. $c$, SCG cells (6 d in culture with NGF) extending processes on cerebellar gray matter but not on white matter $(w m)$; arrows, groups of SCG cells with processes. $d$, High magnification of boxed area in $c$. Neurons sit on top of tissue section, which shows some disintegration at prolonged culture times. $e$ and $f$, Chicken embryo DRGs ( $9 \mathrm{~d}$ in culture, in the presence of NGF) on adult rat cerebellar sections extend processes on gray matter $(\mathrm{gm})$, which stop when they meet white matter $(\mathrm{wm})$. In $f$, the ganglion is sitting on white matter; in this case a short and abortive outgrowth of axons is seen. In $e$, some tissue damage is seen in the vicinity of the ganglion, probably due to the release of proteolytic activity after long times in culture. Staining, Coomassie blue. Magnification, $a, \times 62 ; b$ and $c, \times 30 ; d, \times 150 ; e$ and $f, \times 115$. 

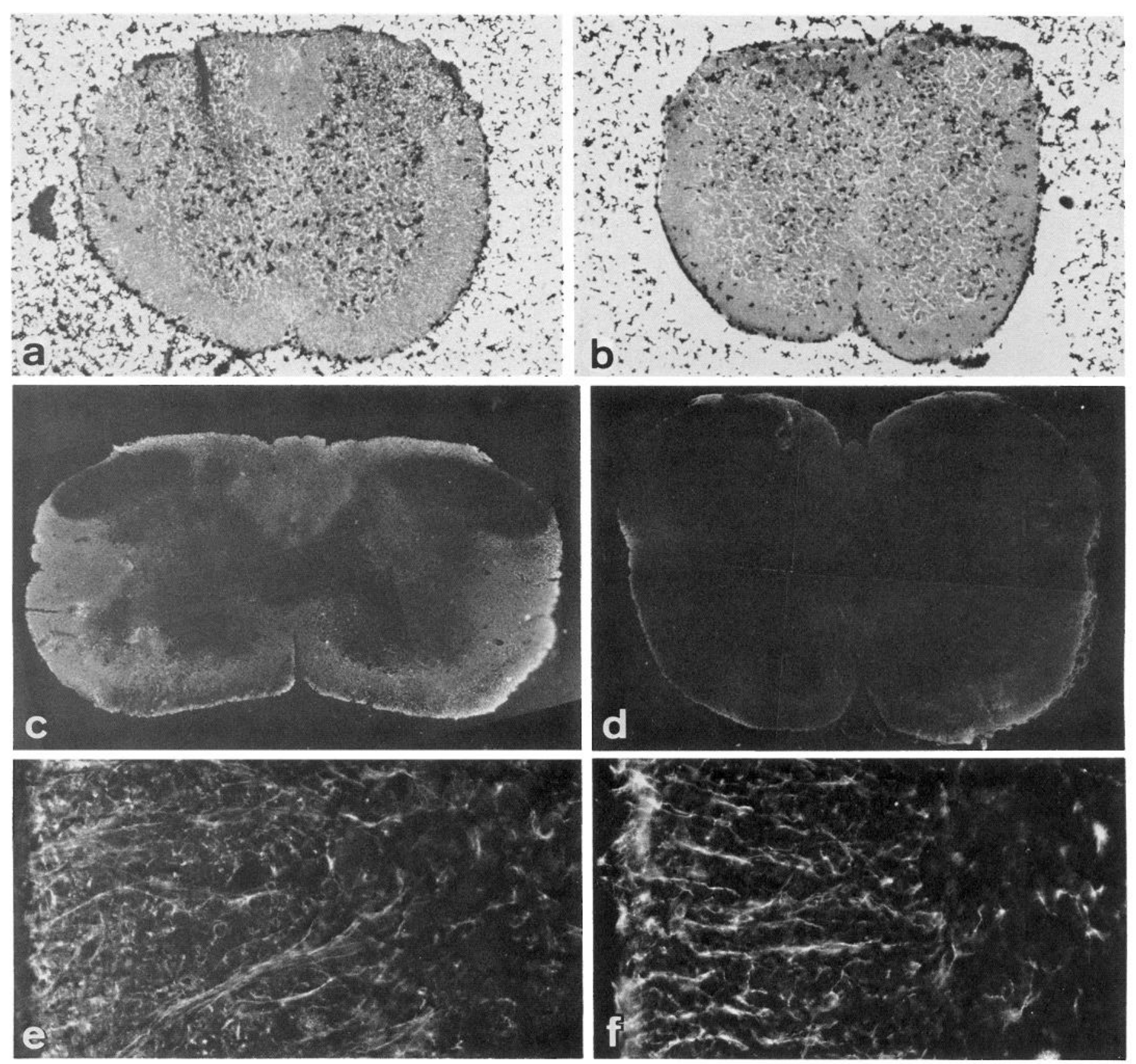

Figure 5. $a$ and $b$, Neuroblastoma cells on spinal cord sections obtained from 5-azacytidine-treated rat (13-d-old) (b) and from a control rat of the same age $(a)$. 5-Azacytidine treatment eliminated the strong preference for gray matter $(b)$, while the control shows a pattern of distribution similar to the adult rat spinal cord $(a)$. Staining. Cresyl violet. $c$ and $d$, A strong reduction in $\mathrm{O}_{1}(\mathrm{GalC})$ immunofluorescence in spinal cord of 5 -azacytidine-treated rat $(d)$ compared with control $(c)$ indicates a strong depression in oligodendrocyte and myelin content. $e$ and $f$, Contrary to myelin constituents, GFAP staining does not show significant modifications after 5 -azacytidine treatment $(f ; e$, control). Spinal cord frozen sections from 13-d-old $(a, b, e, f)$ and from 11-d-old rats $(c, d)$. Magnification, $a-c, \times 35 ; d, \times 47 ; e$ and $f, \times 250$.

The majority of neuroblastoma cells failed to flatten and extend processes on nervous tissue. The few cells sitting on white matter remained round and small, white approximately half of the cells on gray matter extended small sheets of membranes and filopodia. In contrast, many of the cells on the glass coverslip extended processes within $2 \mathrm{~d}$ in culture.

\section{Neuroblastoma cells on adult trout sections}

In contrast to the picture obtained with adult rat nervous tissue, NB-2A cells adhered about equally well to gray and white matter of the trout spinal cord (Fig. 3). Many cells were present on the optic nerve sections, in agreement with the observations of Carbonetto et al. (1987) done with dissociated DRG neurons seeded onto goldfish optic nerves.

\section{Sympathetic and sensory neurons on adult rat sections}

Dissociated SCG and DRG cells from newborn rats were grown on adult rat cerebellar, spinal cord, and optic and sciatic nerve sections. After 2 weeks in culture, many cells adhered and extended processes on the sciatic nerves (Fig. $4 a$ ), whereas no 


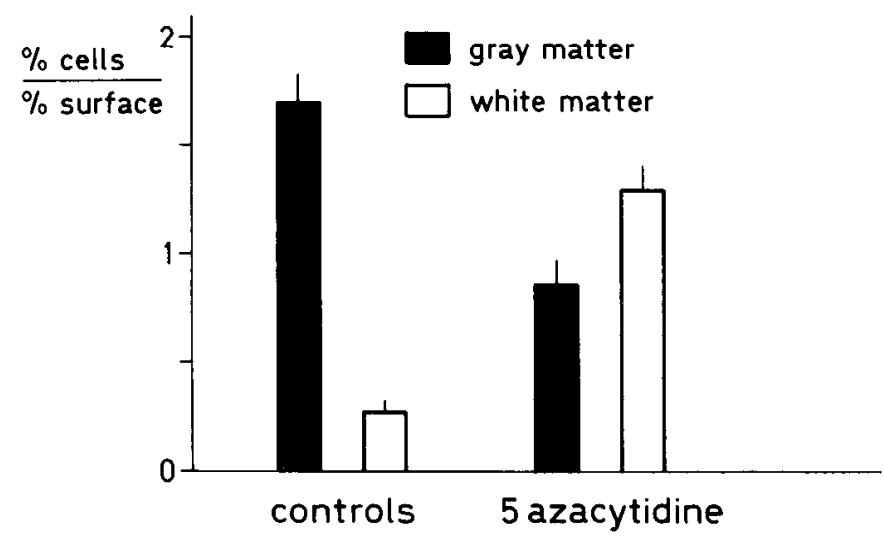

Figure 6. Quantitative detcrmination of ncuroblastoma cclls on spinal cords taken from 5-azacytidine-treated rats and from controls of the same age. Mean \pm SEM out of 6 control rat sections and of 75 -azacytidine-treated rat sections.

neurons or processes were present on the optic nerves (Fig. $4 b$ ). On cerebellar sections, cells were mainly present on the gray matter and extended processes exclusively on gray matter (Fig. $4, c, d)$. Thick bundles of axons from cells sitting on the glass often grew around the tissue sections, without invading the white matter.

DRG explants from chicken embryos were cultured on adult rat cerebellar sections. Ganglia on gray matter showed long processes that extended up to the border of large white matter areas (Fig. 4e). The ganglia sitting on white matter extended only short thick bundles of axons (Fig. $4 f$ ).

As already noted for neuroblastoma cells, gray matter, though permissive for adhesion and axonal elongation, was a poorer substrate than the glass surface around the sections. In fact, after 1 week in culture, while numerous processes grew on glass over long distances, only few and much shorter fibers were present on the tissue sections.

\section{Sections of 5-azacytidine-treated rats}

The results presented up to this point demonstrated that neuronal cells do not adhere and extend their processes on CNS white matter from the adult rat. There are 3 main components of white matter regions: axons, astrocytes, and oligodendrocytes with their product myelin. In order to distinguish between astrocyte and oligodendrocyte influences, we looked for a model in which myelin and oligodendrocytes are strongly reduced. Such a model was introduced by Black et al. (1986), who observed that newborn rats injected with the antimitotic agent 5 -azacytidine subsequently showed an almost complete prevention of myelination and a $88 \%$ decrease of the oligodendrocyte population in optic nerve. We therefore cultured neuroblastoma cells on spinal cord sections of 13-d-old 5-azacytidine-treated rats and of controls of the same age. On the sections of untreated animals, the majority of neuroblastoma cells, again, adhered to the gray matter (Fig. $5 a$ ), although relatively more cells were found on white matter than in the case of adult tissue. This difference is probably due to the still incomplete oligodendrocyte and myelin development. Much in contrast, however, was the distribution of neuroblastoma cells on the 5-azacytidine-treated spinal cords. There, many cells adhered to the white matter, including ventral and dorsal funiculi (Fig. $5 b$ ). Staining of sections witih antibodies specific for myelin glycolipids $\left(\mathrm{O}_{1}\right)$ (Fig.

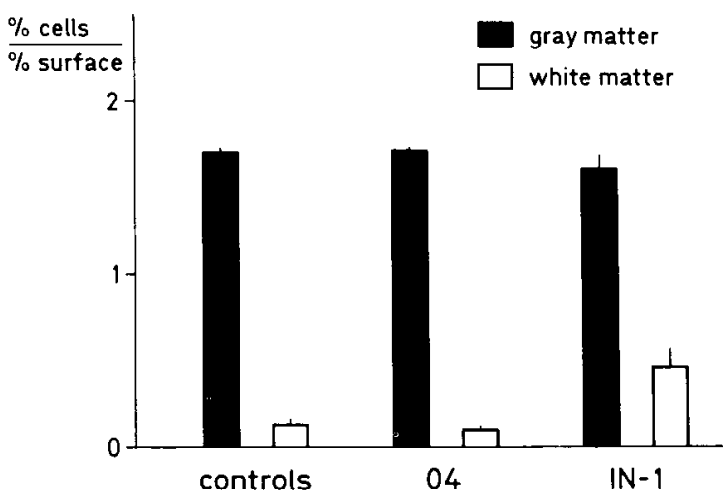

Figure 7. Quantitative determination of neuroblastoma cell density on 28-d-old rat spinal cord sections incubated with antibodies IN-1, $\mathrm{O}_{4}$ as control, or untreated. Mean and \pm SEM of 6 sections; $5000-8000$ cells per section. Cell density increased on white matter regions incubated with IN-1 but not with control antibody.

$5, c, d$ ) and proteins (MBP) (not shown) confirmed the strong reduction of myelination in the 5-azacytidine-treated spinal cords. The density of astrocyte processes as shown by GFAP staining was unchanged (Fig. 5,e,f). The treatment also did not influence the distribution of laminin, which remained confined to pial and blood vessel basal laminas (not shown). The histogram in Figure 6 shows the quantitative determination of neuroblastoma cells on 5-azacytidine-treated rats and on controls. It can be seen that after 5-azacytidine treatment white matter regions become even more permissive than gray matter regions. This could be due to the presence of favorable substrates, whose effects become evident only when the nonpermissive oligodendrocytes are absent.

\section{Sections treated with an antibody against myelin-associated inhibitor $(I N-1)$}

Specific antibodies against oligodendrocyte membrane components inhibiting axon elongation have been produced (IN-1) (Caroni and Schwab, 1988b). Adsorption with these antibodies has been shown to improve the nonpermissive substrate properties of myelin (Caroni and Schwab, 1988b). We have preincubated spinal cord sections of 14- and 28-d-old rats with IN1 , followed by the addition of neuroblastoma cells. Antibodies $\mathrm{O}_{1}$ or $\mathrm{O}_{4}$ (Sommer and Schachner, 1981), which strongly label myelin and oligodendrocytes, were used as control antibodies. The results showed a large increase in the number of cells adhering to the white matter regions in the sections treated with IN-1, compared with untreated or control antibodies treated sections (Fig. 7). Maximal effects with almost complete neutralization of white matter nonpermissiveness were obtained only on 14-d-old rat sections and with purified antibody (data not shown).

\section{$3 T 3$ fibroblasts on adult rat CNS sections}

Interestingly, the nonpermissive substrate property of rat CNS white matter was not restricted to neuronal cells. When we plated $3 \mathrm{~T} 3$ cells at high cell density onto frozen sections of spinal cord or cerebellum taken from adult rats, cells again selectively adhered to gray matter (Fig. 8, $a, b$ ). Significant spreading of the fibroblast also occurred, although to a lesser extent than on glass. 

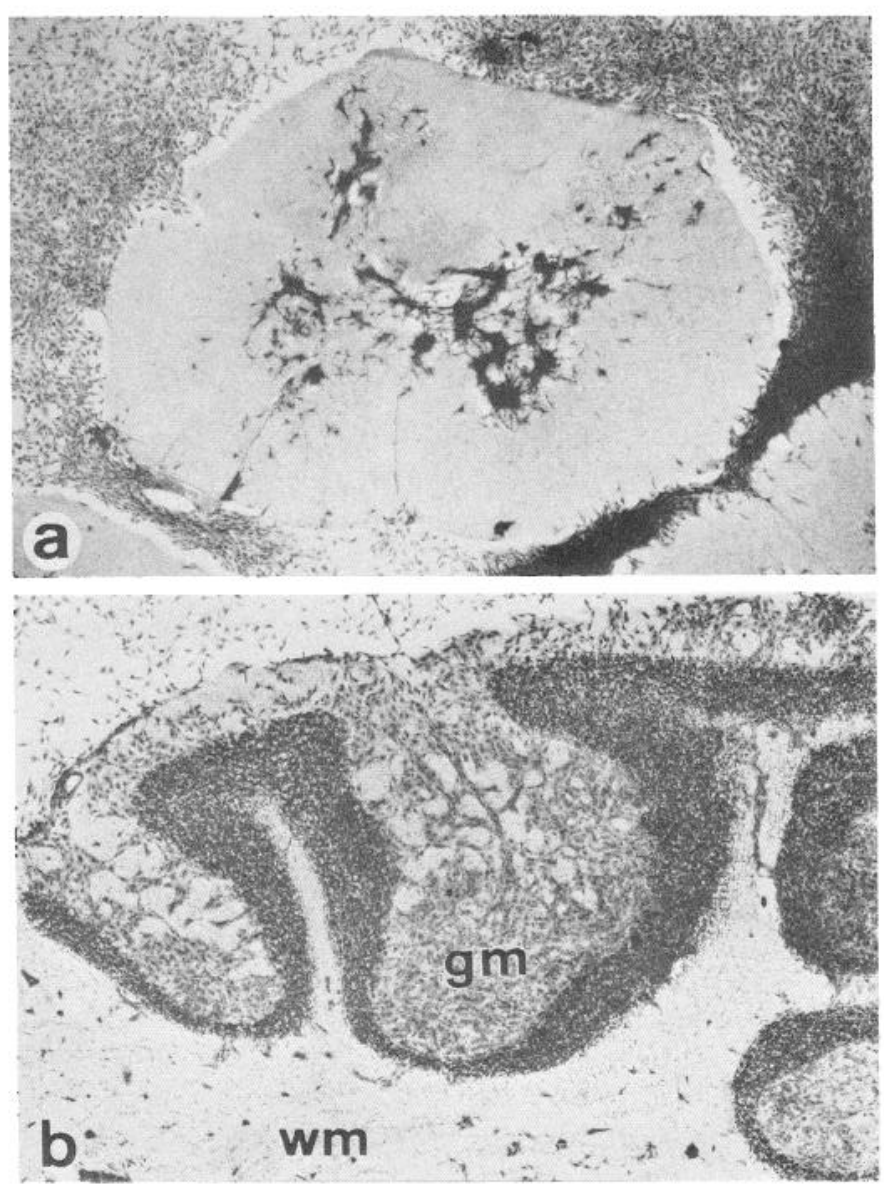

Figure 8. 3T3 cells cultured for $2 \mathrm{~d}$ on frozen sections of adult rat spinal cord $(a)$ and cerebellum ( $b$; courtesy of P. Paganetti). Like neuroblastoma cells, 3T3 cells adhere and flatten preferentially on gray matter regions $(\mathrm{gm}) ; w m$, white matter. Staining, Cresyl violet. Magnification, $a, \times 19 ; b, \times 25$.

\section{Discussion}

In this study we investigated the substrate properties of adult mammalian nervous tissue using frozen sections on which neuronal cells were cultured. The results showed that CNS white matter has a dramatic nonpermissive effect on cell adhesion and fiber outgrowth, in contrast to gray matter areas which allowed cell adhesion and neurite elongation. Such a difference between gray and white matter adhesive properties was not observed in rat sciatic nerve and fish spinal cord. For neuroblastoma cells and dissociated rat sympathetic and sensory neurons fish CNS and mammalian PNS (myelin-containing peripheral nerve) were good substrates, confirming the results of Carbonetto et al. (1987) for chicken DRGs.

Differences in substrate components have been proposed in order to explain the lack of neurite regeneration in the CNS of higher vertebrates. In particular, adult CNS has been suspected to lack favorable substrates, e.g., laminin (Liesi, 1985a; Carbonetto et al., 1987). Laminin is present in some favorable tissue substrates tested for cell adhesion and axonal outgrowth such as adult rat sciatic nerve (Carbonetto et al., 1987), early embryonic rat CNS (Liesi, 1985b; Carbonetto et al., 1987), and mature fish CNS (Hopkins et al., 1985; Liesi, 1985a; Carbonetto et al., 1987), but laminin is also absent in developing CNS during most of the time during which projections are formed in vivo
(Liesi, 1985b). Laminin was undetectable in gray matter in our sections and remained undetectable in gray and white matter also after 5-azacytidine treatment.

CNS white matter is composed of axons, astrocytes, and myelin-producing oligodendrocytes. Our data obtained with 5-azacytidine-treated rats showed that it is possible to obtain a permissive substrate in otherwise nonpermissive regions by strongly suppressing oligodendroglia and myelin formation. This finding correlates well with the recent observation that cultured differentiated oligodendrocytes and purified rat CNS myelin are inhibitory substrates for nerve cell adhesion and fiber outgrowth, as well as for 3T3 cells adhesion and spreading (Schwab and Caroni, 1988). Two membrane proteins present only in differentiated oligodendrocytes and in CNS myelin are responsible for this property (Caroni and Schwab, 1988a, b). In the present experiments on frozen sections, addition of the monoclonal antibody IN-1 against the 2 myelin-associated inhibitory proteins (Caroni and Schwab, 1988b) significantly reduced the nonpermissive substrate effect of spinal cord white matter for neuroblastoma cells. The fact that the inhibitory property could not be neutralized completely could be due (1) to a low affinity and/ or low concentration of IN-1, which, being an IgM, probably also cannot optimally penetrate into the section; (2) to additive "bad substrate" components, e.g., type 2 astrocytes, which differentiate after oligodendrocytes from a common precursor (Raff et al., 1983) and would also be eliminated by 5 -azacytidine treatment. Also, the substrate property of gray matter, which, compared with tissue culture plastic or even glass, was still not very good (as reflected by the poor fiber outgrowth of neuroblastomas and the limited spreading of 3T3 cells), could be due to the presence of some myelin or oligodendrocytes, e.g., in spinal cord, and/or to additional, yet undefined, components.

In all our experiments, neuroblastoma cell adhesion correlated well with axonal elongation of sympathetic or sensory neurons and adhesion and spreading of 3T3 fibroblasts. This was true for adult mammalian sciatic and optic nerve, white and gray matter of spinal cord and cerebellum, and for mature fish spinal cord and optic nerve. This finding is in agreement with the results obtained with living cultured oligodendrocytes or purified myelin as a culture substrate, both of which were equally nonpermissive substrates for neuroblastoma and 3T3 adhesion, as well as for sympathetic or sensory neurite growth (Schwab and Caroni, 1988).

Our findings suggest that the presence of nonpermissive or inhibitory substrate components in CNS white matter, probably associated with mature oligodendrocytes and myelin, could be crucially important for the absence of regeneration in the mammalian CNS. In fact, it is noteworthy that in those in vivo experiments where neurite growth has been obtained through adult CNS tissue, these regenerating fibers were mostly confined to gray matter areas (Kromer et al., 1981; Nornes et al., 1983; Björklund and Stenevi, 1984; Commissiong, 1984).

\section{References}

Benfey, M., and A. J. Aguayo (1982) Extensive elongation of axons from rat brain into peripheral nerve grafts. Nature 296: 150-152.

Björklund, A., and U. Stenevi (1984) Intracerebral neural implants: Neuronal replacement and reconstruction of damaged circuitries. Annu. Rev. Neurosci. 7: 279-308.

Black, J. A., S. G. Waxman, B. R. Ransom, and M. D. Feliciano (1986) A quantitative study of developing axons and glia following altered gliogenesis in rat optic nerve. Brain Res. 380: 122-135.

Carbonetto, S., D. Evans, and P. Cochard (1987) Nerve fiber growth 
in culture on tissue substrata from central and peripheranl nervoùs systems. J. Neurosci. $7: 610-620$.

Caroni, P., and M. E. Schwab (1988a) Two membrane protein fractions from rat central myelin with inhibitory properties for neurite growth and fibroblast spreading. J. Cell Biol. 106: 1281=1288.

Caroni, P., and M. E. Schwab (1988b) Antibody against myelin-associated inhibitor of neurite growth neutralizes non-permissive substrate properties of CNS white matter. Neuron 1: 85-96.

Commissiong, J. W. (1984) Fetal locus coeruleus transplanted into the transected spinal cord of the adult rat: Some observations and implications. Neuroscience 12: 839-853.

Daniloff, J. K., G. Levi, M. Grumet, F. Rieger, and G. M. Edelman (1986) Altered expression of neuronal cell adhesion molecules induced by nerve injury and repair. J. Cell Biol. 103: 929-945.

Hopkins, J. M., T. S. Ford-Holevinski, J. P. McCoy, and B. W. Agranoff (1985) Laminin and optic nerve regeneration in the goldfish. J. Neurosci. 5: 3030-3038.

Johnson, J. E., Y. A. Barde, M. E. Schwab, and H. Thoenen (1986) Brain-derived neurotrophic factor supports the survival of cultured rat retinal ganglion cells. J. Neurosci. 6: 3031-3038.

Kromer, L. F., A. Björklund, and U. Stenevi (1981) Regeneration of the septohippocampal pathways in adult rats is promoted by utilizing embryonic hippocampal implants as bridges. Brain Res. 210: 173200.

Levi-Montalcini, R., and P. U. Angeletti (1968) Nerve growth factor. Physiol. Rev. 48: 534-569.

Liesi, P. (1985a) Laminin-immunoreactive glia distinguish regenerative adult CNS systems from non-regenerative ones. EMBO J. 4: 2505-2511.

Liesi, P. (1985b) Do neurons in the vertebrate CNS migrate on laminin? EMBO J. 4: 1163-1170.

Liuzzi, F. J., and R. J. Lasek (1987) Astrocytes block axonal regeneration in mammals by activating the physiological stop pathway. Science 237: 642-645.

Mains, R. E., and P. H. Patterson (1973) Primary cultures of dissociated sympathetic neurons. J. Cell Biol. 59: 329-345.

Nornes, H., A. Björklund, and U. Stenevi (1983) Reinnervation of the denervated adult spinal cord of rats by intraspinal transplants of embryonic brain stem neurons. Cell Tissue Res. 230: 15-35.

Omlin, F. X., H. deF. Webster, C. G. Palkovits, and S. R. Cohen (1982)
Immunocytochemical localization of basic protein in major dense line regions of central and peripheral myelin. J. Cell Biol. $95: 242=$ 248.

Raff, M. C., R. H. Miller, and M. Noble (1983) A glial progenitor cell that develops in vitro into an astrocyte or an oligodendrocyte depending on the culture medium. Nature $303: 390-396$.

Ramón y Cajal, S. (1928) Degeneration and Regeneration of the Nervous System [English translation and reprint (1959), Hafner, New York].

Reier, P. J., L. J. Stensaas, and L. Guth (1983) The astrocytic scar as an impediment to regeneration in the central nervous system. In Spinal Cord Reconstruction, C. C. Kao, R. P. Bunge, and P. J. Reier, eds., pp. 163-195, Raven, New York.

Richardson, P. M., V. M. K. Issa, and A. J. Aguayo (1984) Regeneration of long spinal axons in the rat. J. Neurocytol. 13: 165-182.

Sandrock Jr., A. W., and W. D. Matthew (1987) An in vitro neuritepromoting antigen functions in axonal regeneration in vivo. Science 237: 1605-1608.

Schwab, M. E., and P. Caroni (1988) Oligodendrocytes and CNS myelin are non-permissive substrates for neurite growth and fibroblast spreading in vitro. J. Neurosci. 8: 2381-2393.

Schwab, M. E., and H. Thoenen (1985) Dissociated neurons regenerate into sciatic but not optic nerve explants in culture irrespective of neurotrophic factors. J. Neurosci. 5: 2415-2423.

Singh, H., and S. E. Pfeiffer (1985) Myelin-associated galactolipids in primary cultures from dissociated fetal rat brain: Biosynthesis, accumulation, and cell surface expression. J. Neurochem. 45: 13711381.

Smith, G. M., R. H. Miller, and J. Silver (1986) Changing role of forebrain astrocytes during development, regenerative failure, and induced regeneration upon transplantation. J. Comp. Neurol. 251: $23-43$.

So, K. F., and A. J. Aguayo (1985) Lengthy regrowth of cut axons from ganglion cells after peripheral nerve transplantation into the retina of adult rats. Brain Res. 328: 349-354

Sommer, I., and M. Schachner (1981) Monoclonal antibodies $\left(\mathrm{O}_{1}\right.$ to $\mathrm{O}_{4}$ ) to oligodendrocyte cell surfaces: An immunocytological study in the central nervous system. Dev. Biol. 83: 311-327.

Thoenen, H., and Y. A. Barde (1980) Physiology of nerve growth factor. Physiol. Rev. 60: 1284-1335. 